\title{
Quality of Informed Consent Among Patients Who Underwent Major Surgical Procedure in a Tertiary Care Hospital, Addis Ababa, Ethiopia
}

This article was published in the following Dove Press journal: Open Access Surgery

\author{
Wuletaw Chane $\mathbb{D}^{1}$ \\ Bethlehem Birhanu ${ }^{2}$ \\ Yisihak Suga' \\ 'Department of Surgery, St. Paul's \\ Hospital Millennium Medical College, \\ Addis Ababa, Ethiopia; ${ }^{2}$ St. Paul's Hospital \\ Millennium Medical College, Addis Ababa, \\ Ethiopia
}

Background: Informed consent is the process by which a patient learns about and understands the purpose, benefits, and potential risks of a medical or surgical intervention and then agrees to receive the treatment. It is a legally required process before performing any medical or surgical procedure. In most setups where surgical services are being provided, most components of informed consent are not always complete. The aim of this study is to assess the quality of informed consent among surgical patients admitted to the surgical ward of SPHMMC (St. Paul's Hospital Millennium Medical College) from March 4 to April 12, 2019, G.C.

Methods and Materials: This is an institution-based prospective cross-sectional study done on patients admitted to the surgical ward of SPHMMC from March 4 to April 12, 2019, G.C. A total of 135 patients were selected by simple random sampling and were interviewed after their surgeries and before discharge.

Results: The informed consent form does not have any of the essential components of surgical informed consent. Out of 135 respondents, only $8.1 \%$ of the patients received the minimum required components of informed consent (a good quality informed consent). $85.9 \%$ were told their diagnosis, $55.6 \%$ knew the benefits of the surgery, and $60.7 \%$ knew the consequences of not doing the surgery. Only $26.7 \%$ of respondents received explanations about the risk of the procedure. $44.4 \%$ of patients were told alternative options of treatment. Conclusion: The quality of informed consent is poor in the surgical ward of SPHMMC. The hospital administration (surgical department) should develop a protocol on the amount of information disclosed to patients before surgery and train all medical personnel.

Keywords: informed, consent, quality

\section{Introduction}

Informed consent is

the process by which a patient learns about and understands the purpose, benefits, and potential risks of a medical or surgical intervention, including clinical trials and then agrees to receive the treatment or participate in the trial. ${ }^{1,2,9,17}$

The principle of informed consent originates from a patient's right to selfdetermination. This means that patients can make decisions about their bodies independently without influence from anyone. $2,5,6,7,8,16$

Informed consent may be used for different purposes in different in contexts: legal, ethical and administrative.
Correspondence: Wuletaw Chane Department of Surgery, St. Paul's Hospital Millennium Medical College, Addis Ababa, Ethiopia

Email wulexc@gmail.com 
Obtaining informed consent is not a process that can be deemed simple. It is affected by a number of limitations that have an impact on its quality and efficacy. For this reason, some methods are suggested that can optimize the process of informed consent. These include

developing a practice of involving patients in decisions (sensitive to patients' preferences for information and their decision-making styles), clearly establishing the goals of care, and prioritize them in the context of the patient's other life goals, encouraging and checking patient comprehension and documenting the process thoroughly. $3,4,14,15$

Informed consent is a relatively novel practice in surgery, which became a standard procedure as surgical practice became more patient-oriented. Several problems affect obtaining a quality informed consent. To mention the few;

patient comprehension, patient's use of disclosed information, patient autonomy, demand on care providers (time, being free from bias), difficulty of physicians to meet minimum requirements. ${ }^{3}$

The above-mentioned problems make obtaining informed consent difficult and might even significantly compromise its quality.

Informed consent for medical procedures is a legal requirement in Ethiopia. It was stated that medical service may not be provided without obtaining the patient's informed consent under the Ethiopian Council of Minister's Regulation 299/2013, article 52. It also states, under subarticle 3, "Any health professional shall make reasonable effort to obtain the patient's informed consent". ${ }^{4}$

As discussed above the achieving basic components of informed consent and its unique problems in a developing country including Ethiopia is a challenge. The aim of this research is to find the gap and to assess the magnitude of the negative impact on quality and adequacy of services, so that reasonable and practical solutions can be suggested.

\section{Materials and Methods}

Institution-based prospective cross-sectional study on patients admitted to the surgical ward of St. Paulo's hospital millennium medical college from March 4 to April 12, 2019, G.C.

The inclusion criteria included those patients who are above 18 years of age, admitted to surgical wards, starting from their first postoperative period and are cooperative. Patients having a mental illness which grossly impedes the study process were not part of the research. Patients who were having a second surgery in the same admission were also excluded to avoid confounding between the two informed consent processes.

The population-adjusted sample size was found to be 135; determined using the formula for a single population proportion based on the following assumptions; confidence interval (CI) $95 \%, \mathrm{Z} 1.96$, margin of sample error $5 \%$ and prevalence $26.5 \%$.

A questionnaire that consists of closed-ended questions was used to interview patients. Though the questionnaire was prepared in English, it was translated into an Amharic version. The data were collected by the researcher and trained medical students. The questionnaires are investigator-administered and consist of three sections: 1) basic demographic information; 2) basic service characteristics, 3) components of informed consent. In order to assess the quality of informed consent sheet used at the surgical ward of SPHMMC, a separate observation checklist was used to document its contents. The collected data were entered into SPSS version 23 for cleaning and analysis. Descriptive statistics (ie, frequency and percentage) were done for the variables.

Permission was obtained from SPHMMC IRB. Written informed consent was obtained from each study subject.

\section{Results}

\section{Sociodemographic Characteristics}

All $(100 \%)$ of the selected patients agreed to participate in the study. The respondents were evenly distributed among the age groups, with $23.7 \%(\mathrm{n}=32)$ young adults, $22.2 \%$ $(\mathrm{n}=30)$ adults, $28.1 \%(\mathrm{n}=38)$ middle-aged patients and $25.9 \%(n=35)$ in the elderly age group. Half $(48.9 \%, n=66)$ of the respondents were male, while the rest $(51.1 \%, \mathrm{n}=69)$ were female. Majority of the respondents are married (71.1\%, $\mathrm{n}=96)$. Orthodox Christianity is the religion where most respondents belonged to $(70.4 \%, \mathrm{n}=95)$. Regarding occupation, $20 \%(\mathrm{n}=27)$ of them are farmers, $14.1 \%(\mathrm{n}=19)$ government employees and a staggering $32.6 \%(n=44)$ of them are unemployed (Table 1).

\section{Basic Service Characteristics}

Majority of the respondents underwent elective surgery $(68.1 \%, \mathrm{n}=92)$, while the rest $(31.9 \%, \mathrm{n}=43)$ had emergency surgery. Half of them were provided information by a physician $(51.1 \%, n=69), 17 \%(n=23)$ by a nurse and $31.9 \%(n=43)$ of them were not aware of the profession of 
Table I Sociodemographic Characteristics of Respondents at Surgical Ward of St. Paul's Hospital Millennium Medical College, Addis Ababa, Ethiopia, 2019

\begin{tabular}{|c|c|c|}
\hline $\begin{array}{l}\text { Sociodemographic } \\
\text { Characteristics }\end{array}$ & $\begin{array}{l}\text { Frequency } \\
(\mathrm{N}=135)\end{array}$ & $\begin{array}{l}\text { Percentage } \\
\text { (\%) }\end{array}$ \\
\hline \multicolumn{3}{|l|}{ Age Group (Years) } \\
\hline $18-25$ & 32 & 23.7 \\
\hline $26-40$ & 30 & 22.2 \\
\hline $4 I-60$ & 38 & 28.1 \\
\hline$>60$ & 35 & 25.9 \\
\hline \multicolumn{3}{|l|}{ Sex } \\
\hline Male & 66 & 48.9 \\
\hline Female & 69 & 51.1 \\
\hline \multicolumn{3}{|l|}{ Education } \\
\hline Cannot read or write & 32 & 23.7 \\
\hline Primary education & 48 & 35.6 \\
\hline Secondary education & 33 & 24.4 \\
\hline College or higher & 22 & 16.3 \\
\hline \multicolumn{3}{|l|}{ Marital Status } \\
\hline Single & 37 & 27.4 \\
\hline Married & 96 & 71.1 \\
\hline Divorced & 2 & 1.5 \\
\hline \multicolumn{3}{|l|}{ Religion } \\
\hline Orthodox & 95 & 70.4 \\
\hline Protestant & 23 & 17 \\
\hline Muslim & 16 & 11.9 \\
\hline Other & I & 0.7 \\
\hline \multicolumn{3}{|l|}{ Occupation } \\
\hline Farmer & 27 & 20 \\
\hline Government employee & 19 & 14.1 \\
\hline Private work & 26 & 19.3 \\
\hline Daily laborer & 7 & 5.2 \\
\hline Unemployed & 44 & 32.6 \\
\hline Other & 12 & 8.9 \\
\hline
\end{tabular}

the person who took the informed consent. Consent was taken the day before the surgery for half of the patients $(53.3 \%$, $n=72$ ), while the remaining received it on the day of the surgery, few minutes before the surgery, or on the OR table (Table 2).

\section{Information Received Prior to the Surgery}

All of the respondents or their families were asked to give informed consent and they agreed. The majority $(85.9 \%$,
Table 2 Basic Service Characteristics Given to Respondents at Surgical Ward of St. Paul's Hospital Millennium Medical College, Addis Ababa, Ethiopia, 2019

\begin{tabular}{|c|c|c|}
\hline $\begin{array}{l}\text { Basic Service } \\
\text { Characteristics }\end{array}$ & $\begin{array}{l}\text { Frequency } \\
(n=135)\end{array}$ & $\begin{array}{l}\text { Percentage } \\
\text { (\%) }\end{array}$ \\
\hline \multicolumn{3}{|c|}{ Profession of the person who took the informed consent } \\
\hline Doctor & 69 & 51.1 \\
\hline Nurse & 23 & 17 \\
\hline I do not know & 43 & 31.9 \\
\hline \multicolumn{3}{|l|}{ Type of the surgery } \\
\hline Emergency & 43 & 31.9 \\
\hline Elective & 92 & 68.1 \\
\hline \multicolumn{3}{|c|}{ Time of signing the informed consent form } \\
\hline The day before the surgery & 72 & 53.3 \\
\hline On the day of the surgery & 33 & 24.4 \\
\hline Few minutes before the & 22 & 16.3 \\
\hline Surgery or on the OR table & 8 & 5.9 \\
\hline
\end{tabular}

$\mathrm{n}=116)$ knew the diagnosis/nature of their illness. However, around half $(57.8 \%, \mathrm{n}=78)$ did not know who would perform the surgery, $88.9 \%(\mathrm{n}=120)$ did not know the estimated duration of the surgery, and $83 \%(n=112)$ were not aware the type of anesthesia planned to be used.

Among the basic components of informed consent, only half $(55.6 \%, \mathrm{n}=75)$ were aware of the benefits of the surgery, and $38.5 \%(\mathrm{n}=52)$ of them did not know the consequences of refusing the surgery. Less than one-third $(26.7 \%, n=36)$ of the patients understood the risks of undergoing the surgery. Nevertheless, the majority $(71.1 \%, \mathrm{n}=96)$ of the patients wanted to know more about these risks. This is true for both groups of patients: those who were and were not told about the risks $(74.7 \%$ and $61.1 \%$, respectively).

The majority $(73.3 \%, \mathrm{n}=99)$ said they were given adequate time for decision, while only half $(51.1 \%, n=69)$ were given the opportunity to ask questions (Table 3 ).

\section{Receipt of Minimum Acceptable Components of Surgical Informed}

\section{Consent}

For this study, the following four were considered what every patient should understand before undergoing any surgical procedure: type/nature of the surgery, benefits of the surgery, risks of the procedure and alternative options of treatment. Surprisingly, only $8.1 \%(\mathrm{n}=11)$ of the patients received all four essential components of SIC, while 17.8\% (24) did not receive any of them at all. The following chart presents the 
Table 3 Components of Informed Consent Provided to Respondents at Surgical Ward of St. Paul's Hospital Millennium Medical College, Addis Ababa, Ethiopia, 2019

\begin{tabular}{|c|c|c|c|}
\hline \multirow[t]{2}{*}{ Components of Informed Consent } & \multicolumn{3}{|c|}{ Responses (n, \%) } \\
\hline & Yes & No & Do Not Remember \\
\hline Signed an informed consent form $(n=135)$ & $135(100)$ & - & - \\
\hline Received information on who would perform the operation $(n=135)$ & $56(4 I .5)$ & $78(57.8)$ & $\mathrm{I}(0.7)$ \\
\hline Told the diagnosis $(n=135)$ & $116(85.9)$ & $19(14.1)$ & - \\
\hline Informed about the type/nature of the surgery $(n=135)$ & $84(62.2)$ & $50(37)$ & $\mathrm{I}(0.7)$ \\
\hline Told the estimated duration of the surgery $(n=135)$ & $12(8.9)$ & $120(88.9)$ & $3(2.2)$ \\
\hline Informed about the benefits of the surgery $(n=135)$ & $75(55.6)$ & $59(43.7)$ & $\mathrm{I}(0.7)$ \\
\hline Told the consequences of not undergoing the surgery $(n=135)$ & $82(60.7)$ & $52(38.5)$ & $\mathrm{I}(0.7)$ \\
\hline Received an explanation about the risks of the treatment $(n=135)$ & $36(26.7)$ & $97(71.9)$ & $2(1.5)$ \\
\hline Wanted more explanation on these risks $(n=135)$ & $96(7 I .1)$ & $39(28.9)$ & - \\
\hline Received an explanation about alternative options for this treatment $(n=135)$ & $60(44.4)$ & $74(54.8)$ & $\mathrm{I}(0.7)$ \\
\hline Told about the type of anesthesia to be used $(n=135)$ & $21(15.6)$ & $112(83)$ & $\mathrm{I}(0.7)$ \\
\hline Got information on potential follow-up treatment (medical/surgical) $(n=135)$ & $39(28.9)$ & $95(70.4)$ & $\mathrm{I}(0.7)$ \\
\hline Given adequate time for decision to sign on the informed consent form $(n=135)$ & $99(73.3)$ & $34(25.2)$ & $2(1.5)$ \\
\hline Given opportunity to ask questions $(n=135)$ & $69(5 \mathrm{I} .1)$ & $65(48.1)$ & I (0.7) \\
\hline
\end{tabular}

percentage of respondents that received the minimum required four components of informed consent (Figure 1).

\section{Clarity of the Surgical Informed Consent}

Patients were asked the degree of clarity of the explanations given to them about the surgical procedures. Almost half $(46.7 \%, \mathrm{n}=63)$ said everything was clear, while $29.6 \%$ (40) said the information is not clear at all (Table 4).

\section{Satisfaction with the Surgical Informed} Consent Process

Patients were asked to assess their level of satisfaction with the informed consent service they received prior to their surgical procedure on a 5-point scale. Half $(51.8 \%$, $\mathrm{n}=70)$ of the patients reported that they were very satisfied $(18.5 \%, \mathrm{n}=25)$ or satisfied $(33.3 \%, \mathrm{n}=45)$ with the service, while $11.1 \%(n=15)$ were dissatisfied, and $12.6 \%{ }^{17}$ were very dissatisfied (Table 5).

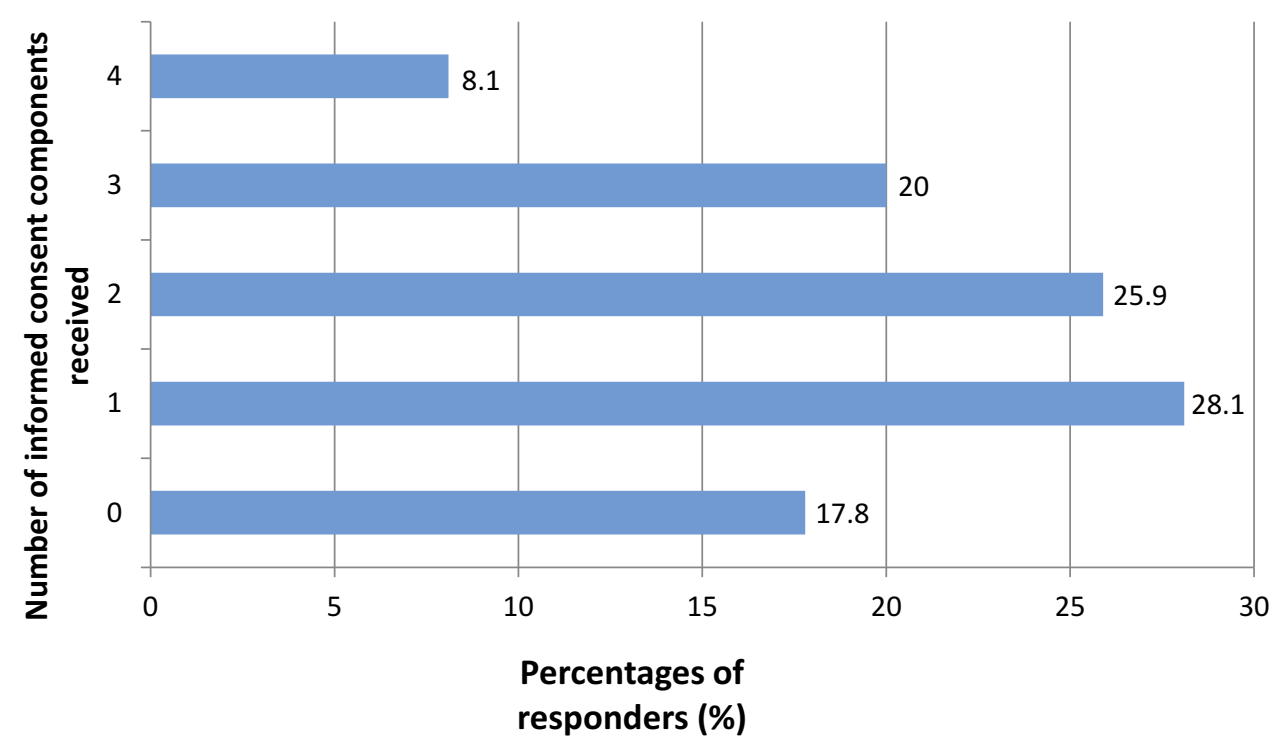

Figure I Number of informed consent components received by Respondents at Surgical Ward of SPHMMC, Addis Ababa, Ethiopia, 2019. 
Table 4 Clarity of Explanations About the Procedure to Respondents at Surgical Ward of St. Paul's Hospital Millennium Medical College, Addis Ababa, Ethiopia, 2019

\begin{tabular}{|l|l|l|}
\hline $\begin{array}{l}\text { Clarity of the Explanations } \\
\text { About the Procedures }\end{array}$ & $\begin{array}{l}\text { Frequency } \\
(\mathbf{n = 1 3 5 )}\end{array}$ & $\begin{array}{l}\text { Percentage } \\
\text { (\%) }\end{array}$ \\
\hline Clear & 63 & 46.7 \\
Partly clear & 32 & 23.7 \\
Not clear & 40 & 29.6 \\
\hline Total & 135 & 100 \\
\hline
\end{tabular}

Table 5 Satisfaction with the SIC Process of Respondents at Surgical Ward of St. Paul's Hospital Millennium Medical College, Addis Ababa, Ethiopia, 2019

\begin{tabular}{|l|l|l|}
\hline $\begin{array}{l}\text { Satisfaction with the Informed } \\
\text { Consent Process }\end{array}$ & $\begin{array}{l}\text { Frequency } \\
(\mathbf{n = 1 3 5 )}\end{array}$ & $\begin{array}{l}\text { Percentage } \\
\text { (\%) }\end{array}$ \\
\hline Veryhigh & 25 & 18.5 \\
High & 45 & 33.3 \\
Neutral & 22 & 16.3 \\
Low & 15 & 11.1 \\
Very low & 17 & 12.6 \\
No opinion & 11 & 8.1 \\
\hline Total & 135 & 100 \\
\hline
\end{tabular}

\section{Informed Consent Sheet}

Patients have to sign their agreement for surgery on an informed consent sheet as a legal requirement before undergoing surgery. In SPHMMC, the informed consent sheet used for this purpose is nonspecific and contains

Table 6 Surgical Ward Informed Consent Form Components at St. Paul's Hospital Millennium Medical College, Addis Ababa, Ethiopia, 2019

\begin{tabular}{|l|l|l|}
\hline $\begin{array}{l}\text { Components of Informed } \\
\text { Consent }\end{array}$ & \multicolumn{2}{|l|}{$\begin{array}{l}\text { Present on Informed } \\
\text { Consent Sheet at Surgical } \\
\text { Ward of SPHMMC }\end{array}$} \\
\cline { 2 - 3 } & Yes & No \\
\hline Nature of the procedure & & $\mathrm{X}$ \\
Benefits of the procedure & & $\mathrm{X}$ \\
Risks of the procedure & $\mathrm{X}$ \\
Type of anesthesia to be used & & $\mathrm{X}$ \\
Duration of the procedure & & $\mathrm{X}$ \\
Alternative treatments & & $\mathrm{X}$ \\
Statement that patient has & & $\mathrm{X}$ \\
understood the information & & $\mathrm{X}$ \\
Statement that the patient has \\
the right to refuse the treatment \\
Source of additional information
\end{tabular}

only general statements that declare the patient's willingness to undergo the surgery (Table 6).

\section{Discussion}

The informed consent sheet used at SPHMMC (Table 6) does not have any of the items listed in the observation checklist. It is nonspecific to any procedure and it appears that its purpose is to avoid legal liability rather than aid the patient in decision-making. It also does not contain statements that inform the patient their right to refuse the treatment or how they can get additional sources of information. Nor does it have declarations that the patient has understood the information given to him/her. In one study done in the USA to assess the contents of informed consent sheets in 157 hospitals, only $26 \%$ of the forms included all 4 basic elements, and only $14 \%$ of the forms seemed to aid patients in decision-making. ${ }^{17}$ Even though this is a low number by itself, the finding in this study is even lower, where NONE of the forms contains any of the basic elements. The inattention to this could be due to regarding the informed consent form merely as a legal document and not a source of information, or it could be due to the limited number of people who are educated enough to read and understand the information that could be presented in the form. ${ }^{18}$

The other source of information was patient interview. This revealed that only $8.1 \%$ of the patients received the minimum required information from an informed consent. The minimum required information being the following for this study: nature of the risks and benefits of the procedure and alternatives to the procedure with their risks and benefits.

In this study, $85.9 \%$ of the patients were told their illness. This is low compared with the study in Greece in $2007 / 08$ in which $100 \%$ of the patients knew their diagnosis. ${ }^{9}$ Although the majority knew their diagnosis in this study too, the aim should be close to $100 \%$. It is unlikely that a patient will know details about the surgery if they do not know their illness in the first place.

Regarding the risks of the procedure, the data varies in different parts of the world. In this study, $26.7 \%$ of the patients received explanations about the risks. The finding in this study was higher than the finding in Pakistan by where only $3.4 \%$ of patients were told the risks. ${ }^{11}$ It is also higher than a study in Hawassa where $11.7 \%$ of the patients knew the risks. ${ }^{13}$ However, it is lower than the practice in Greece in 2007/08 in which $76.6 \%$ of the patients were told the risks of the procedure. ${ }^{9}$ It is also lower than the finding in 2002/04 in 
Israel, in which $39-60 \%$ of the patients understood the risks. ${ }^{10}$ This shows that there is great variation among different countries and that there is a gap in our practice regarding revealing risks to patients. This could be due to physicians' belief that too much information about risks might cause excess anxiety in patients, to the extent of leading them to refuse the surgery. However, this study showed that most patients want to know about the risks of the surgery (71.1\%).

$44.4 \%$ of the respondents were told alternative treatment options (or lack thereof). This is higher compared to studies in Hawassa, ${ }^{13}$ Pakistan ${ }^{12}$ and Israel, ${ }^{10}$ in which $24.3 \%, 21.7 \%$ and $8-20 \%$ of the patients were given information on alternative treatment options, respectively.

In this study, half $(55.6 \%)$ of the patients knew the benefits of the surgery; which is lower compared to a study in Greece, ${ }^{9}$ in which $88.3 \%$ of the patients were aware of the benefits. In another study in Hawassa, ${ }^{13} 87 \%$ of the patients understood the benefits of the surgery, which is a higher number than this study. This shows poor practice of including patients in decision-making.

Slightly more than half $(60.7 \%)$ of the patients understood the consequences of refusing the surgery in this study. This number is higher than was found in a study in Pakistan, where only $4.3 \%$ of patients had this information. ${ }^{11}$ In Hawassa, $48.3 \%$ of the study participants knew the consequences, ${ }^{13}$ which is lower than the finding in this study. The higher number here could be due to physicians' attempt to convince the patient to agree to the surgery, by telling them what would happen if they refuse the surgery.

Majority (73.3\%) of the patients said they had adequate time for decision in this study. However, only $30.9 \%$ of the patients agreed with this according to a study in Hawassa. ${ }^{13}$ This higher number could be attributed to the fact that most of the surgeries were elective and patients are admitted for surgery after a long wait for free beds, in which case they could use that time to deliberate their decision.

Half $(51.1 \%)$ of the patients said they were given the opportunity to ask questions. This is a better number than was found in a study in Pakistan, in which only $39.4 \%$ of the respondents could ask questions. ${ }^{11}$ In contrast, a higher proportion (80.9\%) of the patients was given the chance to ask questions in a study in Hawassa. ${ }^{13}$ The lower number here could be due to the high patient load and lack of time on the part of physicians for an in-depth discussion with each patient.

Regarding the clarity of the explanations in the informed consent process, $29.6 \%$ of the respondents reported they were not clear, while the rest said they were either clear or partially clear. This is low compared to a study in Pakistan, where $54.7 \%$ of the patients said the explanations were not clear. ${ }^{12}$ One third of the respondents were not clear on the explanations given for them. This may be due to inadequate opportunity to ask questions, fear of asking explanation, language barrier or use of technical/medical words by physicians.

Half $(51.5 \%)$ of the patients in this study were either satisfied or very satisfied with the informed consent process in this study. This is lower than other similar studies: $83 \%, 80 \%$ and $62.1 \%$ of respondents rated the informed consent process satisfactory in studies in Greece, ${ }^{9}$ Israel $^{10}$ and Hawassa ${ }^{13}$ respectively. This could be due to the inadequacy of the information given to patients, unclear information, or poor involvement of patients in the decision-making process.

In conclusion, the quality of informed consent is poor in the surgical ward of SPHMMC. The informed consent form does not contain any of the minimum accepted components of informed consent. Only a small number of patients were given information about all the basic four components of surgical informed consent. The hospital administration (surgical department) should develop a protocol on the amount of information disclosed to patients before surgery, and train all medical personnel giving service to surgical patients accordingly. Medical/surgical trainings should, as part of medical ethics courses, encourage physicians to have shared decisionmaking processes with their patients, and respect patients' rights to self-determination.

\section{Limitations of the Study}

In this study, we have considered two main limitations. The first is social desirability bias: Patients were interviewed while they were still in the hospital. This might cause them to alter their responses to what they believe is desired in hopes of better treatment. The second one is recall bias: Patients might have forgotten information given to them during the informed consent process since they were interviewed after the surgery.

\section{Disclosure}

The authors report no conflicts of interest in this work.

\section{References}

1. Paterick TJ, Carson GV, Allen MC, Paterick TE. Medical informed consent: general considerations for physicians. Mayo Clin Proc. 2008;83(3):313-319. doi:10.4065/83.3.313

2. Laforet EG. The fiction of informed consent. JAMA. 1976;235 (15):1579-1585. doi:10.1001/jama.1976.03260410035020 
3. Hall DE, Prochazka AV, Fink AS. Informed consent for clinical treatment. Cmaj. 2012;184(5):533-540. doi:10.1503/cmaj.112120

4. Birile M. Perception About Informed Consent for Surgical Procedures as Part of Patient Safety Practice Among Service Providers and Patients in Addis Ababa Hospitals [Doctoral dissertation]. Addis Ababa Universty; 2017.

5. Murray PM. The history of informed consent. Iowa Orthop J. 1990;10:104.

6. McCullough LB. Was bioethics founded on historical and conceptual mistakes about medical paternalism? Bioethics. 2011;25(2):66-74. doi:10.1111/j.1467-8519.2010.01867.x

7. Corrigan O. Empty ethics: the problem with informed consent. Sociol Health Illn. 2003;25(7):768-792. doi:10.1046/j.1467-9566.2003.00 369.x

8. Irabor DO, Omonzejele P. Local attitudes, moral obligation, customary obedience and other cultural practices: their influence on the process of gaining informed consent for surgery in a tertiary institution in a developing country. Dev World Bioeth. 2009;9(1):34-42. doi:10.1111/j.1471-8847.2007.00198.x

9. Falagas ME, Akrivos PD, Alexiou VG, et al. Patients' perception of quality of pre-operative informed consent in Athens, Greece: a pilot study. PLoS One. 2009;4(11):e8073. doi:10.1371/journal.pone.000 8073

10. Brezis M, Israel S, Weinstein-Birenshtock A, Pogoda P, Sharon A, Tauber R. Quality of informed consent for invasive procedures. Int J Qual Health Care. 2008;20(5):352-357. doi:10.1093/intqhe/ mzn025

11. Jawaid M, Farhan M, Masood Z, Husnain SM. Preoperative informed consent: is it truly informed? Iran J Public Health. 2012;41(9):25.
12. Siddiqui FG, Shaikh JM, Memon MM. An audit of informed consent in surgical patients at a university hospital. J Ayub Med Coll Abbottabad. 2010;22(1):133-135.

13. Teshome M, Wolde Z, Gedefaw A, Tariku M, Asefa A. Surgical informed consent in obstetric and gynecologic surgeries: experience from a comprehensive teaching hospital in Southern Ethiopia. BMC Med Ethics. 2018;19(1):38. doi:10.1186/s12910-018-0293-2

14. Ochieng $\mathrm{J}$, Ibingira $\mathrm{C}$, Buwembo $\mathrm{W}$, et al. Informed consent practices for surgical care at university teaching hospitals: a case in a low resource setting. BMC Med Ethics. 2014;15(1):40. doi:10.1186/14726939-15-40

15. Nnabugwu II, Ugwumba FO, Udeh EI, Anyimba SK, Ozoemena OF. Informed consent for clinical treatment in low-income setting: evaluating the relationship between satisfying consent and extent of recall of consent information. BMC Med Ethics. 2017;18(1):69. doi:10. 1186/s12910-017-0227-4

16. Sivanadarajah N, El-Daly I, Mamarelis G, Sohail MZ, Bates P. Informed consent and the readability of the written consent form. Ann $R$ Coll Surg Engl. 2017;99(8):645-649. doi:10.1308/ rcsann.2017.0188

17. Bottrell MM, Alpert H, Fischbach RL, Emanuel LL. Hospital informed consent for procedure forms: facilitating quality patient-physician interaction. Arch Surg. 2000;135(1):26-33. doi:10.1001/archsurg.135.1.26

18. Biros MH, Lewis RJ, Olson CM, Runge JW, Cummins RO, Fost N. Informed consent in emergency research: consensus statement from the coalition conference of acute resuscitation and critical care researchers. JAMA. 1995;273(16):1283-1287. doi:10.1001/jama. 1995.03520400053044
Open Access Surgery

\section{Publish your work in this journal}

Open Access Surgery is an international, peer-reviewed, open access journal that focuses on all aspects of surgical procedures and interventions. Patient care around the peri-operative period and patient outcomes post-surgery are key topics for the journal. All grades of surgery from minor cosmetic interventions to major surgica procedures are covered. Novel techniques and the utilization of new

Submit your manuscript here: https://www.dovepress.com/open-access-surgery-journa instruments and materials, including implants and prostheses that optimize outcomes constitute major areas of interest. The manuscript management system is completely online and includes a very quick and fair peer-review system, which is all easy to use. Visit http://www.dovepress.com/testimonials.php to read real quotes from published authors. 